\section{Fat content and fatty acid composition of pooled banked milk}

The amount of fat in human milk is influenced by diurnal variations in fat content, by the stage of lactation, and, more importantly, by the method of milk collection-namely, whether it is expressed or dripped. ${ }^{1}$ In human milk banks milk is usually pooled, and pooling is generally assumed to result in a more uniform fat content. We compared the fat contents in pooled banked human milk and a commercially available formula milk. We also analysed the fatty acid composition of pooled banked human milk and compared our findings with those published by the Department of Health and Social Security. ${ }^{2}$

\section{Methods and results}

We obtained milk samples from 22 batches of pooled human milk arriving at the special care baby unit from the milk bank, and from SMA ready to feed formula milk for infants. The human milk had been collected by three or four mothers at home over one to five days and stored in the freezing compartment of a domestic refrigerator; after thawing this milk was pooled

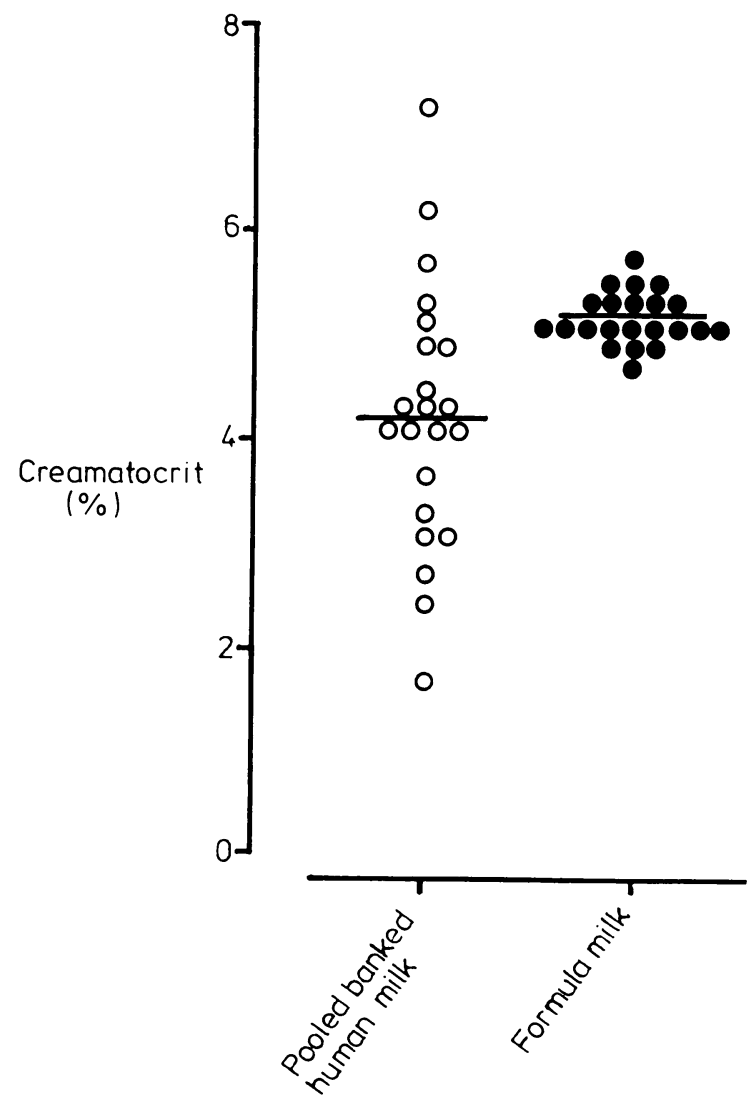

Distribution of creamatocrit values in 22 samples of pooled banked milk and 22 of a formula milk. Each value is the mean of three determinations in a single milk specimen. Horizontal lines indicate mean values.

in $200 \mathrm{ml}$ containers. It consisted of expressed breast milk and milk that had dripped from the opposite breast when the baby was being fed.

We measured the fat content of the milk by the creamatocrit method. ${ }^{3}$ Milk triglycerides were separated by thin layer chromatography, and the fatty acid composition was determined by gas-liquid chromatography. ${ }^{4}$ Mean creamatocrit values were compared by Student's $t$ test.

In pooled banked human milk the maximum creamatocrit, $7 \cdot 26 \%$, was nearly four times greater than the minimum creamatocrit, $1 \cdot 72 \%$, and a third of the creamatocrit values were below $4 \%$ (figure). By contrast, the creamatocrit values in formula milk were distributed over a fairly narrow range $(4 \cdot 75-5 \cdot 26 \%)$. The mean creamatocrit in formula milk (5.16 (SD $0 \cdot 19) \%$ ) was significantly greater than that in pooled human milk $(4 \cdot 21$ $(1 \cdot 24))(\mathrm{p}<0.001)$ (figure).

Comparison of the fatty acid composition of our pooled banked human milk with that of mature human milk analysed by the Department of Health and Social Security ${ }^{2}$ showed that our milk contained more linoleic acid and linolenic acid (polyunsaturated fatty acids $C 18: 2$ and $C 18: 3$ ) but less lauric acid (saturated fatty acid $\mathrm{C} 12: 0$ ). In our 22 specimens of pooled banked milk the mean proportions of linoleic, linolenic, and lauric acids were $11.2 \%, 1.2 \%$, and $2.7 \%$; the proportions reported by the Department of Health and Social Security were $7 \cdot 2 \%, 0 \cdot 8 \%$, and $5 \cdot 4 \%$ respectively.

\section{Comment}

Our study shows that pooling specimens of human milk whose fat content is not known may not result in milk with a uniform fat content. Newborn infants cannot be assured of an adequate energy intake from any one specimen of pooled human milk owing to the variability in fat content. In this respect formula milk has a clear advantage as its fat content is standardised. Pooled milk might be improved by routine measurement of the fat content in donated human milk. The milk might then be mixed to ensure that the fat content is within an acceptable range.

The change in the fatty acid composition of human milk coincides with a trend towards inclusion in the diet of more fat from vegetable sources than from animal sources. Vegetable fat contains a larger proportion of unsaturated fatty acids, and it appears that this change in intake of fatty acids has altered the fatty acid composition of human milk. ${ }^{5}$

We thank Dr J Smart and Dr V Miller for their helpful comments, Ms J Glazier for technical help, Professor R D H Boyd for encouragement, and Mrs E Evans for secretarial help.

1 Spencer SA, Hull D. Fat content of expressed breast milk: a case for quality control. Br Med $\mathcal{f} 1981 ; 282: 99-100$.

2 Working Party on the Composition of Foods for Infants and Young Children. The composition of mature human milk, report. London: HMSO, 1977 (Chairman T E Oppé). (Reports on Health and Social Subjects No 12.)

${ }^{3}$ Lucas A, Gibbs JAH, Lister RLJ, Baum JD. Creamatocrit: simple clinical technique for estimating fat concentration and energy value of human milk. Br Med 7 1978; :1018-20.

4 Danon A, Heimberg M, Oates JA. Enrichment of rat tissue lipids with fatty acids that are prostaglandin precursors. Biochim Biophys Acta $1975 ; 388: 318-30$.

${ }^{5}$ Guthrie HA, Picciano MF, Sheehe D. Fatty acid patterns of human milk. F Pediatr 1977;90:39-41.

(Accepted 23 September 1983)

Department of Child Health, St Mary's Hospital, Manchester M13 0JH

L SMITH, MB, MRCP, clinical tutor and registrar

A HARKES, BSC, biochemist

$S$ W D'SOUZA, PHD, FRCP, senior lecturer and consultant paediatrician

Correspondence to: Dr $S \mathbb{W}$ 'Souza.

\section{Effect of digoxin and vitamin $E$ in preventing cardiac damage caused by doxorubicin in acute myeloid leukaemia}

The anthracycline antibiotics doxorubicin and daunorubicin are widely used to treat acute leukaemia and solid tumours, but their usefulness is limited by myocardial damage related to dosage above $550 \mathrm{mg} / \mathrm{m}^{2}$ body surface area. ${ }^{1}$ The cause is uncertain, but vitamin $\mathrm{E}$, a powerful antioxidant that limits lipid peroxidation, has inhibited cardiac damage in mice ${ }^{2}$ and strophanthin has reduced cardiac damage in dogs and rabbits, ${ }^{3}$ perhaps by competitive inhibition with doxorubicin at cardiac receptor sites. 